\title{
Virtual autopsy and community engagement for outbreak response in Africa: traditional, religious and sociocultural perspectives
}

Shane O'Sullivan ${ }^{1^{*}} \mathbb{D}$, Mohammed Imran Sajid ${ }^{2}$, Folashade B. Agusto ${ }^{3}$, Joseph Mwangangi ${ }^{4}$, Angellar Manguvo ${ }^{5}$, Dominic Wichmann ${ }^{6}$ and Magdy Kharoshah ${ }^{7}$

\begin{abstract}
Background: In response to outbreaks, the manner in which the medical field engages with the process of death is significantly important, not only in the pathological but also in the sociocultural aspect. Certain response-methodology used could be a critical catalyst for community resistance to post-mortem examinations (e.g. hiding corpses, violence), considering how the deceased are handled in different cultures. We reviewed the traditional, religious and sociocultural aspects of post-mortem response-methodology in Africa. With no means to take blood samples, innovative sampling techniques were developed and frequently adopted in post-mortem cases. However, this approach can be met with resistance.
\end{abstract}

Main body: To avoid resistance, virtual autopsy (virtopsy) involving a non-invasive or minimally invasive imaging-guided biopsy (e.g. portable ultrasound guidance) is recommended as a proper entry point to negotiations around examination of the deceased. We outline how adapting virtopsy and community engagement strategies can have many benefits to communicable disease prevention or control, public health and communities in Africa and elsewhere. This paper provides a completely new perspective by applying imaging autopsy to field studies. These are usually hospital-based procedures. Many countries can train their response and military personnel on how to perform a safe straightforward virtopsy procedure in an outbreak situation. Just as relevant, Islam is now the fastest growing religion in the world — virtopsy might appease fears and increase the autopsy rate among large Muslim populations (in Africa and elsewhere).

Conclusions: Virtopsy use and its application might have proved very useful in the recent outbreak of Ebola in 2014 and microcephaly associated with Zika virus. Use of virtopsy may have reduced the number of Ebola cases worldwide and enabled an earlier diagnosis linking Zika virus to microcephaly during the recent outbreak in Northeast Brazil. If the diagnosis was made earlier, additional cases of Ebola or Zika may have been prevented. The issue of invasive autopsy was in all likelihood one of the greatest factors that drove Ebola underground; it prevented communities from cooperating with non-native response teams and contributed to the excessive duration and length of the outbreak. Healers may unknowingly infect others (via scarification) and themselves (via contact with others). Adapting sociocultural engagement methods and conducting a virtopsy may be more acceptable, thereby ameliorating the spread of a deadly virus more efficiently.

Keywords: Minimally invasive autopsy, Non-invasive autopsy, Ebola, Zika, Quarantine, Islamic medicine, Traditional medicine, Witchcraft, Scarification, Witch doctor

\footnotetext{
* Correspondence: doctorshaneosullivan@gmail.com

'Department of Pathology, Faculdade de Medicina, Universidade de São

Paulo, São Paulo/SP, Brazil

Full list of author information is available at the end of the article
} 


\section{Background}

Since 1976, there have been multiple Ebola outbreaks in Africa (Manguvo and Mafuvadze 2015). The most significant example of this in recent years has been the 2014 crisis in West Africa. During outbreaks, non-native response teams encountered situations where patients had died many days before being found. This is because some of the deceased bodies had been purposely hidden from response teams to evade post-mortem examinations. Some community members simply did not declare that they hosted someone sick or deceased in their home, in order to avoid isolation or invasive autopsy (Manguvo and Mafuvadze 2015).

With no means to take blood samples, response teams took skin snip or tissue samples instead. Those samples sometimes had to be transported to the nearest network/ Reference laboratories or even as far as Global Reference centres [such as Centre for Disease Control and Prevention (CDC) in Atlanta, USA]. In the case of CDC, laboratory teams essentially examined samples to search for the Ebola virus; this route could take weeks to determine whether an unusual death was actually Ebola or not.

When deceased bodies were later found and in the case of an extremely decomposed or an exhumed body, innovative sampling techniques were developed. These involved primarily receiving training to use a 15-cm-long cardiac needle to obtain a blood sample. The needle is inserted directly through the deceased patient's chest to access the left ventricle of the heart. Undertaking this technique, response teams may usually find sufficient blood for sampling, which they can then send to their local mobile laboratory and obtain diagnosis within $24 \mathrm{~h}$. This innovation was developed in the field by practitioners who required urgent results. However, these types of invasive autopsy techniques can be resisted by some community members, who hold strong traditional, religious, or spiritual beliefs especially about the sanctity of the deceased (Manguvo and Mafuvadze 2015; Sajid 2016a). This invasive needle approach could therefore potentially lead to an increasing number of hidden corpses.

\section{Traditional perspectives}

In most cultures, supporting relatives through illness is an absolute requirement. For many cultures in remote regions of Africa, an inability to care for a relative is considered a huge failure (Manguvo and Mafuvadze 2015; Sajid 2016a). Secondly, when a relative dies, families are mindful and hold profound duties to protect the spirit of that individual as they pass to the next world or afterlife (Manguvo and Mafuvadze 2015; Sajid 2016a). Taking West Africa as an example, many communities continue to maintain a very high level of their traditional ancestral beliefs, in relation to handling deceased bodies (Manguvo and Mafuvadze 2015; Sajid 2016a); this is a factor to be considered and greatly respected in response to outbreaks.

During the 2014 Ebola outbreak, the general consensus was that relatives did not want the deceased's body to be mutilated, moved, taken away, or placed in a black body bag. Their motives were based on their inherently held beliefs regarding the advent of death and the process of bidding farewell to their relatives. This resulted in hidden chains of transmission that then resurfaced elsewhere. It became clear later that this led to non-reporting of important and significant events by individuals along the chain.

\section{Religious perspectives}

Unfortunately, traditional and other religious or spiritual practices associated with death resulted in further transmission of the disease. Burial/funeral customs were another major cause of amplification reported by response teams in the Ebola outbreak (Manguvo and Mafuvadze 2015). For example, part of the funeral tradition in many African countries involves relatives washing the body and clearing out body orifices (Manguvo and Mafuvadze 2015; Sajid 2016a). Burials without prior consent from relatives of the deceased and invasive autopsies were the main causes of mistrust (Manguvo and Mafuvadze 2015). Relatives would also perceive that the deceased's body was taken away from them for nefarious reasons (Manguvo and Mafuvadze 2015).

Furthermore, non-native response workers attempted to educate and negotiate with healers to stop treatment by scarification. Scarification is a common practice; some healers used a knife to treat Ebola by making very precise scars on the body of a person in order to release demons (Manguvo and Mafuvadze 2015). Through the method of scarification, healers unknowingly but highly effectively have transmitted a virus from one person to another (Manguvo and Mafuvadze 2015; Sajid 2016b). Response workers often spent hours, days, or even weeks negotiating with healers in order to stop these ritual acts. It was noted that there were alternative situations when the healers would make such incisions-this was occasionally observed in epileptic patients, often interpreted as demonic attacks, although some healers would alternatively prescribe herbal concoctions too (Manguvo and Mafuvadze 2015). Moreover, human-to-human transfers by direct contact with body fluids have resulted in healers themselves becoming infected (Manguvo and Mafuvadze 2015).

\section{Sociocultural perspectives}

The previously mentioned situations were not necessarily confined to the autopsy, but also indicated sociocultural engagement and anthropological investigation into the traditions, customs, or belief systems. In addition, the 
Ebola outbreak demonstrated how response workers could have engaged more effectively to achieve successful community cooperation in such situations. On a regular basis, response workers and others in the field can find themselves addressing local officials over community members hiding deceased bodies. In continents other than Africa, it would seem correct to suggest that the hiding of corpses be deemed a crime. However, in Africa, addressing authority issues by introducing new laws or penalties can potentially start sociocultural conflicts in affected countries.

As scientists, we have to approach these situations differently. It may happen that response workers, quickly and inadvertently, make a situation worse for themselves and lead unintentionally to the end of all negotiations around post-mortem examinations or treatment for the living. To avoid this, it is important to adapt sociocultural engagement techniques for various types of African communities, particularly when crossing into social science. Proper sociocultural engagement could lead to successful negotiations that prevent further disasters that may then lead to violence or outbreaks. Therefore, a more appropriate course of action can be adopted that begins with the principle of recognising that essentially these traditional, religious, or spiritual beliefs be considered to have at least equal importance as science; this can be a more practical starting point for sociocultural engagement.

\section{Main text}

Taking any form of sample from a deceased patient has inherent life-threatening risks for response workers (Manguvo and Mafuvadze 2015). Issues arise during the removal of bodies, filling body bags, safe burials, mass burials and even cremation. What these issues give rise to is not just the proposal of an unwelcomed burial or an invasive autopsy, it relates to the deceased and how the deceased are managed in different cultures (Manguvo and Mafuvadze 2015; Sajid 2016a; Sajid 2016b; Al-Saif et al. 2016; Madadin et al. 2014; Marshall and Smith 2015). This affects the capacity to undertake autopsy, sampling, or safe burials.

\section{Virtual autopsy (virtopsy)}

There is a deep chasm between what scientists want to undertake and how communities perceive it from traditional, religious, or spiritual points of view. Therefore, we need to engage in the kind of research, investigation and dialogue that will lead us to a mutually acceptable solution. One of these could be virtopsy. This is an innovative technique for overcoming the concerns, needs and requirements of one side and the scientific aims of the other. It can serve as a proper entry point to negotiations around the examination of the deceased.
One of the unique advantages to virtopsy is using hand-held devices [e.g. portable ultrasound (US)] for non-invasive or minimally invasive imaging-guided biopsy. In poor or remote regions, these devices could serve as an alternative when better resolution imaging scans are unavailable [e.g. magnetic resonance imaging (MRI) or computed tomography (CT)]. Portable ultrasound devices open the possibility to obtain tissue samples for histological and molecular diagnosis in areas that have experienced outbreaks of communicable diseases or regions where the aetiology is unknown.

For an outbreak situation in remote regions where a top-level high-security laboratory is unavailable, very few interventions are possible without basic personal protection equipment. It is likely that portable ultrasound-guided Tru-Cut needle biopsy can be the only option. The ultrasound cannot differentiate communicable causes from others. It only guides the needle so that major organs or fluid accumulations can be punctured. At night, ultrasound can also be used in the darkness of a medical tent when lighting is not available. In brief, such use of portable ultrasound-guided biopsy might have been very useful in these outbreaks (O'Sullivan et al. 2017). In addition, ultrasound-guided needle biopsy could have been highly effective in quickly identifying the cause of the outbreak (O'Sullivan et al. 2017). This approach may have reduced the number of Ebola cases worldwide. Moreover, this could have potentially enabled an earlier diagnosis linking Zika virus to microcephaly recently in Northeast Brazil (O'Sullivan et al. 2017). If the diagnosis was made earlier, additional cases may have been prevented. Earlier diagnosis may make it possible to devise protection policies that greatly reduce the number of individuals who are affected by Ebola or Zika virus.

However, these portable technologies are still not as reliable as conventional virtopsy technologies (e.g. MRI or CT). In general, ultrasound imaging cannot match these technologies in terms of data quality, detail and resolution. Nevertheless, these hand-held devices cost far less and may be the best alternative for individuals with metallic heart valves, pacemakers, implanted cardiac defibrillators, or high body mass index (preventing them from being able to physically fit in a medical imaging scanner)-currently unsuitable for conventional virtopsy. Diagnosis with these portable devices can potentially prevent contamination and spread of communicable diseases in such regions, as well as increasing public acceptance of usage.

Establishing virtopsy as a feasible alternative to conventional autopsy not only increases acceptance among certain populations, it can also lead to identifying more pathogens and increasing scientific discoveries or advancements in the years ahead. A recent study aimed at determining the diagnostic accuracy of post-mortem 
MRI, CT and CT-guided biopsy (with conventional autopsy used as reference standard) was based on 100 consecutive adult patients who died in a hospital setting (Wagensveld et al. 2018). The authors found that combining MRI with biopsies had high sensitivity and specificity for detecting acute and chronic myocardial ischaemia (Wagensveld et al. 2018).

Non-invasive or minimally invasive virtopsy response work is very straightforward but extremely significant. Many countries can train their response and military personnel on how to perform a safe virtopsy procedure in an outbreak situation. It is also possible to overcome any education and training limitations by investing in human capital and local capacities who are able to carry out a proper response. Developed regions in Africa have the capacity to facilitate and cater for virtopsies using MRI or CT machines. An alternative, non-invasive technique (e.g. virtopsy) is ideal for developed Muslim countries such as Saudi Arabia, Qatar, Brunei, United Arab Emirates, Oman, Kuwait, Bahrain and Malaysia, among others. The world's Muslim population is expected to rapidly grow from 23\% (ca. 1.6 billion) in 2010 to $30 \%$ (nearly 2.8 billion) in 2050 . Muslims are expected to grow twice as fast as the overall global population (Pew Research Center 2015). Europe's Muslim population is projected to grow by $63 \%$, increasing from $5.8 \%$ (43 million) in 2010 to $10.2 \%$ (71 million) in 2050 (Pew Research Center 2015).

The goal should be to maintain autopsy, but with the inclusion of this updated, innovative methodology, as a core science in understanding diseases. Response teams should listen, understand and adapt their scientific vocabulary, using appropriate descriptions and examples, before engaging with African communities and then introducing an innovative alternative such as virtopsy.

\section{Community engagement}

In terms of the scientific field, there is a misinterpretation concerning traditional, religious or spiritual beliefs and there has previously been unwillingness to adapt to them (Manguvo and Mafuvadze 2015; Sajid 2016a), and this leads to a breakdown in trust. There is the need for a proper understanding of indigenous community traditions, customs or belief systems. Response groups may find that engaging with these African communities in an appropriate respectful manner results in a compromise that works effectively. This could prevent the blaming of religion or belief systems as the cause of spreading diseases. The focus should be maintained on trying to gain a better understanding of how the international medical/ scientific world can engage with these communities more successfully (Sajid 2016a; Al-Saif et al. 2016; Madadin et al. 2014; Marshall and Smith 2015). Therefore, the first step is to find ways in which non-native healthcare practitioners can perform the necessary scientific work (e.g. virtopsy), whilst simultaneously being sensitive to the local importance of traditional, religious or spiritual beliefs (Sajid 2015).

The second step taken to avoid conflict is engaging with leaders or influential individuals in these villages (Manguvo and Mafuvadze 2015). These leaders or influential individuals sometimes include chiefs, village headmen, church pastors, mosque imams, religious leaders, spiritual leaders and even healers. The term healer can also relate to diviners, traditional healers, spiritual healers, traditional doctors, witch doctors, sorcerers or medicine men/women, among others. These leaders or influential individuals usually hold extremely influential power within these communities (Manguvo and Mafuvadze 2015; Sajid 2016a; Sajid 2016b; Marshall and Smith 2015).

In the past, in some remote regions of Africa, if a person was suspected by a healer to have carried a disease into their village, the consequences led to violent ritual executions of that person by the villagers. Rumours or horror stories of these tragic events can build up reluctance among non-native aid workers who would be willing to volunteer and travel to these remote regions of Africa. The Ebola outbreak of 2014 had a very slow number of volunteers in the early stages of the outbreak (2-3 months delay) (Gates 2015), which is a factor that also contributed to the undue duration and length of the outbreak. On the other hand, non-native charity/aid workers need to have had sufficient professional background checking for suitability and should receive training in reducing their own ability to transmit disease to the locals they are caring for, as well as those in their country of origin upon their return. A number of cases in the media discussed health care workers returning to their countries with Ebola (e.g. in 2014, one of the cases involved a nurse from Scotland that volunteered in Sierra Leone, who then fell ill on return to Glasgow) (Gulland 2016).

For Christians/Muslims, their imams and pastors may play a major role in reaching out to many people. In relation to Christianity as a religion in Africa, there are issues surrounding 'devil worship' which is a thorny issue in the faith. There is a belief that body parts are removed and used for sinister motives associated with Satanism. The majority of Muslims (in Africa and elsewhere) are opposed to invasive autopsy; this is due to religious reasons, burial delays or abhorrence of what they consider the mutilation of the dead. Universal objection of conventional autopsy has led to the search for verbal autopsy and non-invasive or minimally invasive alternatives (e.g. virtopsy); needle biopsy can be found to be less invasive, whereas imaging is found to be a non-invasive substitute of autopsy.

Islamic advances (such as catgut sutures in surgery, informed consent for surgery, prophetic medicine, the first 
ever university and teaching hospitals as we know them today) have evidently helped science, for instance, from medieval Islamic times to modern era science. Abu'l Qasim al-Zahrawi (born in Spain 936 AD) is considered the greatest medieval surgeon to have appeared from the Islamic World; he has been described as the father of surgery and authored the Kitab at-Tasrif (a 30-volume Arabic encyclopaedia on medicine and surgery that included pictures and details of many new surgical instruments).

There is a common misconception that Islam has only recently surfaced as a major religion or that the number of Muslims has only increased recently in Europe following arrival of migrants and refugees. Islam has been a part of Europe for a long time (Shah 2011; Chaudhary 2017; Redžić 2005). Jean de Joinville (chronicler of Medieval France and the Crusades) reported that he was rescued by a Saracen doctor in 1250-the Crusaders testified that they depended upon Arab doctors on frequent occasions. Avicenna's 'The Canon of Medicine' (1025) was translated and disseminated worldwide-he noted the contagious nature of numerous communicable diseases and attributed these to 'traces' left in the air by a sick person. A united approach using inspirational techniques from the past and findings in the present would lead to beneficial outcomes in the future.

In the current climate, it would be more credible and appropriate if the lead on this comes from physicians/ scientists (providing an evidence-based approach) working jointly in cooperation with communities (including Muslims) to champion this cause and increase worldwide education of alternative choices to the conventional autopsy genuinely now available, with the potential for this to be available at no extra cost to them (Lancashire County Council 2018; Sajid 2016a; Sajid 2016b; Sayligil and Ozden 2014; Speech by HRH Prince Charles at Oxford centre for Islamic studies 1993; Sterns 2015; Sajid and Sajid 2007; Madadin et al. 2014; Saad Foundation n.d.). This post-mortem issue can also be negotiated by members of the academic or theological fields willing to deal with those representing the health, medical or scientific fields. A similar strategy proved successful for polio programs; these involved deep negotiations to overcome resistance to vaccinations, based on them being 'haram' (an act that is forbidden by Allah) as opposed to being 'halal' (permissible).

\section{Conclusions}

This paper presented a core approach that is an important starting point applicable in many African countries and elsewhere. It clarifies how non-native response teams should engage with African cultures to prevent the spread of infectious or haemorrhagic diseases. We outlined the compelling benefits of conducting virtopsy amidst strong contradictory belief systems. During the West African Ebola outbreak of 2014, there were major issues surrounding hidden corpses. Non-native response teams responding to an outbreak frequently reported funerals and burials as being genuine sites of Ebola amplification. There were also major issues surrounding the transmission of Ebola by scarification or other methods used by healers.

Besides conflicts over burials, there were also conflicts between invasive autopsy and African traditions, customs or beliefs. For those reasons, there was a lot of resistance and objection to non-native interventions. On the contrary, virtopsy could be considered a more culturally acceptable manner to most African communities; as such, its adoption may go a long way in fostering cooperation and trust between affected communities and western-based intervention workforces.

In Africa, lack of alternatives to invasive autopsy and opposition by influential leaders or healers may have contributed to the lack of cooperation with non-native response teams and the undue duration of the 2014 outbreak. Some local people did not declare that they were hosting sick people or hiding corpses due to fear based on beliefs, fear of being ostracised by the community or fear of not being allowed to ritually cleanse/bury deceased loved ones correctly in preparation for the afterlife. We also emphasise how non-native response teams need to have had sufficient professional background checks completed for their suitability, for example receiving training in reducing their own ability to transmit disease to the locals they are caring for, as well as their country of origin upon their return. Moreover, the 2014 outbreak had a very slow number of volunteers in the early stages (2-3 months delay), which is a factor that also contributed to the excessive duration and length of the outbreak.

Adapting sociocultural engagement methods could overcome objections (due to traditions, customs or beliefs) and encourage people to stop hiding corpses. We consider the importance of addressing sociocultural aspects in response to outbreaks; these are highly important for those in the scientific sector. To acknowledge and respect cultural issues, the international scientific community must be at the forefront in approaching influential leaders and healers in the community. Community-based awareness campaigns specifically targeting these influential leaders or healers can be highly effective for the monitoring and implementation of preventative measures. An alternative, non-invasive technique (e.g. virtopsy) might be the solution.

\footnotetext{
Abbreviations

AD: Anno Domini; CDC: Centre for Disease Control and Prevention; $\mathrm{CT}$ : Computed tomography; MRI: Magnetic resonance imaging; US: Ultrasound; Virtopsy: Virtual autopsy
}

Acknowledgements

We thank the organisation CNPQ (Brazilian National Council for Scientific and Technological Development). This entity provided support that was invaluable to our research. 
Funding

None.

\section{Availability of data and materials}

Not applicable.

\section{Authors' contributions}

The final manuscript was produced, reviewed and approved by all of the authors collectively.

\section{Ethics approval and consent to participate}

Not applicable.

\section{Consent for publication}

Consent to publish was obtained from all participants.

\section{Competing interests}

The authors declare that they have no competing interests.

\section{Publisher's Note}

Springer Nature remains neutral with regard to jurisdictional claims in published maps and institutional affiliations.

\section{Author details}

'Department of Pathology, Faculdade de Medicina, Universidade de São Paulo, São Paulo/SP, Brazil. ${ }^{2}$ Department of Upper GI Surgery, Wirral University Teaching Hospital, Birkenhead, UK. ${ }^{3}$ Department of Ecology and Evolutionary Biology, University of Kansas, Kansas, USA. ${ }^{4}$ KEMRI, Centre for Geographic Medicine Research, Coast, Kilifi, Kenya. ${ }^{5}$ School of Medicine, University of Missouri-Kansas City, Missouri, USA. ${ }^{6}$ Department of Intensive Care, University Hospital Hamburg Eppendorf, Hamburg, Germany. ${ }^{7}$ Forensic Medicine Center in Dammam, Dammam, Kingdom of Saudi Arabia.

Received: 3 April 2018 Accepted: 6 November 2018

Published online: 30 November 2018

\section{References}

Al-Saif DM, Al-Faraidy MA, Madadin MS, Al-Bayat Ml, Al-Sowayigh KS et al (2016) The attitude of people with an Arabic Islamic cultural background toward medico-legal autopsy. Aust J Forensic Sci 48(5):557-563. https://doi.org/10. 1080/00450618.2015.1110200

Chaudhary V (2017) The forgotten Muslim heroes who fought for Britain in the trenches. https://www.theguardian.com/world/2017/nov/12/forgottenmuslim-heroes-fought-for-britain-first-world-war. Accessed 10 Oct 2017.

Gates B (2015) Perspective. The next epidemic — lessons from Ebola. N Engl J Med 372:1381-1384. https://doi.org/10.1056/NEJMp1502918.

Gulland A (2016) UK nurse who contracted Ebola is readmitted to hospital. BMJ 352:i1134. https://doi.org/10.1136/bmj.i1134

Lancashire County Council. Available from: https:/www.lancashire.gov.uk/birthsmarriages-and-deaths/deaths/coroners/non-invasive-post-mortem-examination/. Accessed 10 Sept 2018.

Madadin M, Kharoshah MA (2014) Autopsy in Islam and current practice in Arab Muslim countries. J Forensic and Leg Med 23:80-83. https://doi.org/10.1016/j. jflm.2014.02.005

Manguvo A, Mafuvadze B (2015) The impact of traditional and religious practices on the spread of Ebola in West Africa: time for a strategic shift. Pan Afr Med J 22(Suppl 1):9. https://doi.org/10.11694/pamj.supp.2015.22.1.6190

Marshall K, Smith S (2015) Religion and Ebola: learning from experience. Lancet 0005:e24-e25. https://doi.org/10.1016/S0140-6736(15)61082-0

O'Sullivan S, Holzinger A, Zatloukal K, Saldiva P, Sajid Ml et al (2017) Machine learning enhanced virtual autopsy. Autops Case Rep 7(4):3-7. https://doi.org/ 10.4322/acr.2017.037

Pew Research Center (2015) The future of world religions: population growth projections, 2010-2050. http://assets.pewresearch.org/wp-content/uploads/ sites/11/2015/03/PF_15.04.02_ProjectionsFullReport.pdf. Accessed 10 Oct 2017.

Redžić E (2005) Bosnia and Herzegovina in the Second World War. Published by Frank Cass 2005, p 143 https://books.google.co.uk/books?id= pVCX3jerQmYC\&pg=PA143\&lpg=PA143\&dq=ismet + popovac\&source=b|\&ots= fR6UTWn-KQ\&sig=emP1VMzWzjND0KrGf_s5OoLkrRs\&hl=en\&sa=X\&ved= OahUKEwi8_bCq17vXAhWGdpoKHTfCA1gQ6AEITZAJ\#v=onepage\&q= ismet\%20popovac\&f=false. Accessed 10 Oct 2017
Saad Foundation. http://www.saadfoundation.com/index.php?option=com_ content\&view=article\&id=6\&ltemid=6. Accessed 10 Oct 2017.

Sajid MI (2015) Quality of health care - (definition, general information, history of quality in health care, how it is assessed and which parameters are under evaluation. Quality of health care indicators, etc). Masaryk University Public Health Seminar Paper. https://doi.org/10.13140/RG.2.1.2161.0007. https:// www.researchgate.net/publication/292996613_Quality_of_Health_Care_-Definition_general_information_history_of_quality_in_health_care_how_it_ is_assessed_and_which_parameters_are_under_evaluation_Quality_of_ health_care_indicators_etc. Accessed 10 Oct 2017.

Sajid MI (2016a) Autopsy in Islam: considerations for deceased Muslims and their families currently and in the future. Am J Forensic Med Pathol 37(1):29-31. https://doi.org/10.1097/PAF.0000000000000207

Sajid MI (2016b) Hijama therapy (wet cupping) - its potential use to complement British healthcare in practice, understanding, evidence and regulation. Complement Ther Clin Pract 23:9-13. https://doi.org/10.1016/j.ctcp.2016.01.003

Sajid MI, Sajid I (2007) Islam: faith and medicine. Student BMJ 15:307. https://doi. org/10.1136/sbmj.0709307

Sayligil O, Ozden H (2014) A written consent form dating back to 1524 in Bursa Ser'iye (Sharia Court) records and a proposal of a new start date for consent forms. Ann Saudi Med 34(5):433-436. https://doi.org/10.5144/0256-4947.2014.433

Shah ZH (2011) Islamic contributions to Medieval Europe. The Muslim Times. https://themuslimtimes.info/2011/12/11/islamic-contributions-to-medievaleurope/. Accessed 10 Oct 2017.

Speech by HRH Prince Charles at Oxford centre for Islamic studies (1993) Islam and the West. http://www.islamicentre.org/articles/west.htm. Accessed 10 Oct 2017.

Sterns O (2015) Muslim inventions that shaped the modern world. http://edition.cnn. com/2015/07/22/world/muslim-inventions/index.html. Accessed 10 Oct 2017.

Wagensveld IM, Blokker BM, Pezzato A, Wielopolski PA, Renken NS et al (2018) Diagnostic accuracy of postmortem computed tomography, magnetic resonance imaging, and computed tomography-guided biopsies for the detection of ischaemic heart disease in a hospital setting. Eur Heart J Cardiovasc Imaging. https://doi.org/10.1093/ehjci/jey015

\section{Submit your manuscript to a SpringerOpen ${ }^{\circ}$ journal and benefit from:}

- Convenient online submission

- Rigorous peer review

- Open access: articles freely available online

- High visibility within the field

- Retaining the copyright to your article

Submit your next manuscript at $\boldsymbol{\nabla}$ springeropen.com 